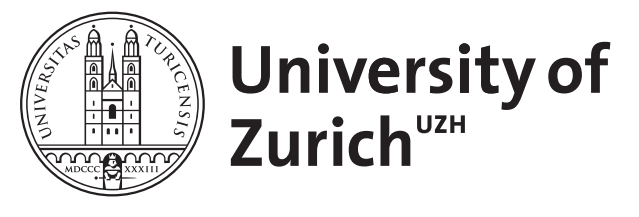

\title{
Epigenetic modifications in rheumatoid arthritis, a review
}

\author{
Klein, Kerstin ; Gay, Steffen
}

\begin{abstract}
Rheumatoid arthritis is an autoimmune disease characterized by chronic joint inflammation and progressive destruction of cartilage and bone which leads to ultimately loss of function and pain. Activated synovial fibroblasts are key effector cells in the pathogenesis of rheumatoid arthritis. In the recent years, epigenetic changes including DNA methylation, histone acetylation and other histone modifications were identified that are associated with an intrinsic activation and the aggressive phenotype of these cells. So far, no therapies targeting rheumatoid arthritis synovial fibroblasts exist. This review comprises recent research efforts that propose epigenetic mechanisms behind the activation of rheumatoid arthritis synovial fibroblasts and other cell types.
\end{abstract}

DOI: https://doi.org/10.1016/j.coph.2013.01.007

Posted at the Zurich Open Repository and Archive, University of Zurich

ZORA URL: https://doi.org/10.5167/uzh-76669

Journal Article

Accepted Version

Originally published at:

Klein, Kerstin; Gay, Steffen (2013). Epigenetic modifications in rheumatoid arthritis, a review. Current Opinion in Pharmacology, 13(3):420-425.

DOI: https://doi.org/10.1016/j.coph.2013.01.007 
Epigenetic modifications in rheumatoid arthritis, a review

Kerstin Klein ${ }^{1}$, Steffen Gay ${ }^{1}$

${ }^{1}$ Center of Experimental Rheumatology, University Hospital Zurich and Zurich Center of Integrative Human Physiology (ZIHP), Zurich, Switzerland

Corresponding author:

Prof. Steffen Gay

Gloriastrasse 23

$\mathrm{CH}-8091$ Zurich

Switzerland

Phone: +4144255 5737

Fax: +41442554415

kerstin.klein@usz.ch

steffen.gay@usz.ch 


\begin{abstract}
Rheumatoid arthritis is an autoimmune disease characterized by chronic joint inflammation and progressive destruction of cartilage and bone which leads to ultimately loss of function and pain. Activated synovial fibroblasts are key effector cells in the pathogenesis of rheumatoid arthritis. In the recent years, epigenetic changes including DNA methylation, histone acetylation and other histone modifications were identified that are associated with an intrinsic activation and the aggressive phenotype of these cells. So far, no therapies targeting rheumatoid arthritis synovial fibroblasts exist. This review comprises recent research efforts that propose epigenetic mechanisms behind the activation of rheumatoid arthritis synovial fibroblasts and other cell types.
\end{abstract}

\title{
Keywords
}

Synovial fibroblast, histone, acetylation, methylation, sumoylation 
Rheumatoid arthritis (RA) is an autoimmune disease characterized by a systemic inflammation, joint destruction, disability and pain. Despite enormous research efforts the underlying cause of the disease is unknown and still no cure exists. Joint resident rheumatoid arthritis synovial fibroblasts (RASF) emerged as key players in the pathogenesis of RA. In addition to macrophages and lymphocytes, also RASF are capable of producing a large set of inflammatory cytokines and chemokines and thereby actively contribute to the inflammatory state in RA. Their intrinsic activation, the inhibition of apoptosis and the recruitment of inflammatory cells including macrophages and lymphocytes, are the major reasons for the excessive hyperplasia of the synovial tissue in RA joints [1]. The importance of these cells in disease progression was further emphasized by functional studies of RASF in the severe immune deficient (SCID) mouse model; RASF, co-implanted with cartilage under the renal capsule of SCID mice were shown to be capable not only to invade into cartilage in the absence of a functioning immune system but also to migrate [2].

This review comprises recent research efforts that reveal the mechanisms behind the intrinsic activation of RASF by investigating epigenetic changes (Figure 1) and summarizes data available from other cell types.

\section{What is epigenetics?}

Originally, epigenetic mechanisms were considered as heritable changes in gene function that were not explainable by changes in the DNA sequence. A more revised definition of epigenetics is the structural adaption of chromosomal regions in order to register, signal or perpetuate altered activity states [3]. Epigenetic modifications including DNA methylation and covalent histone modifications such as acetylation, methylation and ubiquitination alter the accessibility of DNA to the transcription machinery. An increasing amount of proteins that attach ("writers") or remove ("erasers") modifications to DNA and histones or that bind ("readers") to a specific epigenetically modified site have emerged as key players in the regulation of gene expression [4]. Most chromatin marks are highly dynamic and have the capability of influencing transcription by multiple mechanisms; first, they designate chromatin structure and therefore, determine the accessibility of DNA for regulatory proteins; second, they recruit remodeling enzymes that utilize the hydrolysis of ATP to reposition nucleosomes; and third, they mediate the cooperation between pioneer and secondary transcription factors [5].

Most research so far focused on the role of 5-methylcytosine (5-mC) in CpG-rich regions, known as $\mathrm{CpG}$ islands. $\mathrm{CpG}$ islands are enriched in promoters in vicinity to transcriptional start sites and their methylation has been associated with long term gene silencing including 
X-chromosome inactivation. Methylation of DNA is regulated by the activity of DNA methyl transferases (DNMTs) [6].

Histone acetylation on lysines is regulated by the opposing activity of two enzyme families, histone acetyl transferases (HATs) and histone deacetylases (HDACs). Histone acetylation neutralizes lysine's positive charges, an action that has the potential to weaken the interactions between DNA and histones. HDACs are thought to stabilize the local chromatin structure by restoring the positive charges in lysine residues. Therefore, they are mainly considered as transcriptional repressors [5].

Unlike acetylation, histone methylation does not alter the charge of histone proteins. Histone methylation mainly occurs at lysine and arginine residues of histones $\mathrm{H} 3$ and $\mathrm{H} 4$ which can be mono-, di- (lysines, arginines) and trimethylated (lysines) [5]. Depending on the position and the degree of methylation, histone methylation marks can be associated with transcriptional activation or silencing. The polycomb repressive complex 2 with its enzymatic subunit histone methyltransferase enhancer of zeste homologue $2(E Z H 2)$ is responsible for the trimethylation of the repressive mark H3K27me3 (Histone 3 lysine 27 trimethylation) [7]. Today two families of proteins, the lysine-specific demethylase family and the Jumonji $C$ family are known to have histone demethylase activity [8].

In contrast to the above described histone modifications, histone ubiquitination and sumoylation result in larger covalent modifications of histones. Whereas ubiquitination can be associated with transcriptional silencing, as well as with transcriptional initiation and elongation, histone sumoylation is associated with repressive functions. Sumoylation targets mainly histone lysines that are modified by the action of E1, E2, and E3 enzymes which covalently attach small ubiquitin-like modifier molecules (SUMO) [5].

In the following sections we discuss recent findings on the impact of DNA methylation and histone modifications studied so far in the context of RA (Figure 2, Table 1).

\section{DNA methylation}

RASF display a DNA methylome signature that distinguishes them from osteoarthritis synovial fibroblasts (OASF) and normal SF $[9,10]$. Whereas Karouzakis et al. described a global hypomethylation in RASF compared to OASF [9], Nakano et al. investigated both hypo- and hypermethylation patterns in RASF [10]. A global hypomethylation was also found in peripheral blood mononuclear cells (PBMCs) isolated from RA patients compared to healthy controls [11]. Hypomethylation was identified in key genes relevant for RA and related to multiple pathways including cell migration, adhesion, transendothelial migration and extracellular matrix interactions and was associated with an increased gene expression 
[10]. Interestingly, DNMT1, the active enzyme in somatic cells for converting cytosine into 5methylcytosine (5-MeC) using S-adenosyl methionine (SAM) as a methyl-donor, is reduced in RASF compared to OASF [9]. Furthermore, an increased expression of S-adenosyl methionine decarboxylase (AMD), spermidine/ spermine N1-acetyltransferase (SSAT1) and of polyamine-modulated factor 1-binding protein 1 (PMFBP1) led to an increased recycling of polyamines and a reduced amount of SAM and 5-MeC, and was associated with hypomethylation in RASF [12]. Beside global changes in methylome signatures in RA, an altered methylation status of single gene promoters, including promoters for DR3 [13], IL6 [14,15], IL10 [16,17], IL1R2 [17] and CXCL12 [18] was described in PBMCs and RASF. Further evidence for the role of DNA methylation in the pathogenesis of RA and a possible explanation for the increased risk of women to develop RA came from studies investigating the pattern of $X$-chromosome inactivation. Female RA patients exhibited an increased skewed X-chromosome inactivation pattern compared to controls [19] and the promoter of the $\mathrm{X}$ chromosome encoded gene CD40L was demethylated in $\mathrm{CD} 4^{+} \mathrm{T}$ cells from female but not male RA patients [20]. These data clearly show a functional consequence of altered DNA methylation patterns in RA. The results from Karouzakis et al. $[9,12]$ suggested that a supplementation with SAM and/ or the inhibition of the polyamine recycling pathway could be a new promising therapeutic strategy in the treatment of RA and the first therapy that targets the intrinsically activated phenotype found in RASF.

\section{Histone methylation}

Studies looking at histone methylation in the context of RA are scarce. The histone methyltransferase EZH2 was shown to be overexpressed in RASF compared to OASF [21]. EZH2 generates the trimethyl mark on histone 3 lysine 27 (H3K27me3) which is associated with the transcriptional silencing of genes [7]. The tumor suppressor gene secreted frizzledrelated protein 1 (SFRP1), an inhibitor of the wingless type MMTV integration site (Wnt) signaling pathway, was show to be a target of EZH2 activity in RASF. EZH2 overexpression had no impact on global histone trimethylation in RASF [21]. Recently, the involvement of H3K27me3 marks in the pathogenesis of systemic lupus erythematous (SLE) [22] and systemic sclerosis (SSc) [23] were reported. Further studies in RA are needed to clarify the role of histone methylation marks in this autoimmune disease.

\section{Histone acetylation}

In the last eight years certain beneficial effects of HDAC inhibitors in therapeutic as well as preventive approaches in different animal models of RA have been reported [24-28]. Although some decrease in disease severity was shown, these studies have in common that the used inhibitors lack specificity for a single HDAC isoform and the underlying mechanisms 
remained obscure. Also, there are some discrepancies in the literature about HDAC expression and activity in synovial tissues of RA and OA patients [29,30], as well as in RASF [31]. Recently, Kawabata et al. reported that TNF- $\alpha$ increased the expression of HDAC1 and nuclear HDAC activity in RASF [30], suggesting that changes in synovial HDAC activity maybe secondary to local inflammatory changes [32]. Also, Niederer et al. discovered that Sirtuin 1 (SIRT1), a member of the NAD+ dependent Class III histone deacetylases, is over expressed in RA tissues and expression levels were further increased by stimulation of RASF with TNF- $\alpha$. The authors convincingly showed that SIRT1 overexpression promoted the pro-inflammatory cytokine production in monocytes and RASF, and inhibited apoptosis in RASF [33]. Several recent studies investigated effects of different HDAC inhibitors in vitro. The HDAC3 specific inhibitor MI192 was shown to inhibit the LPS-induced expression of TNF- $\alpha$ and IL1- $\beta$ in PBMCs derived from RA patients and healthy controls [34]. The Class I and Class II HDAC inhibitor trichostatin A (TSA) as well as the Class III HDAC inhibitor nicotinamide reduced the TNF- $\alpha$-induced expression of IL6 and the LPS-stimulated expression of IL6 and TNF- $\alpha$ in macrophages of RA patients. Interestingly, this study could not confirm an association between the HDAC inhibitor-dependent acetylation of $\mathrm{H} 3$ and $\mathrm{H} 4$ and the ability of these HDAC inhibitors to regulate cytokine production in macrophages [35]. A growing number of non-histone proteins has been identified as targets for acetylation including signaling molecules, transcription factors and structural proteins. Reversible lysine acetylation in these proteins regulates cellular processes such as the control of mRNA stability, protein localization and degradation, protein-protein as well as protein-DNA interactions [36]. Recently, Grabiec et al. reported that the HDAC inhibitors TSA and ITF2357 reduced IL6 mRNA stability in macrophages and RASF. However, the identified mechanism was not applicable for the regulation of IL8 and MMP1 [37]. Furthermore, the HDAC inhibitors MS-275 and SAHA suppressed the LPS-induced nuclear accumulation of NF-KB p65 in human rheumatoid arthritis synovial fibroblastic E11 cells and THP1 monocytes [38]. These results point to the fact that not all observed beneficial effects of HDAC inhibitors in vitro and in vivo are due to epigenetic modifications and that there is a variety and likely gene-specific mode of action of different HDAC inhibitors on defined target genes.

Furthermore, nutritional influences might significantly alter the state of acetylation. For example, three to six hours after broccoli sprout consumption HDAC activity is reduced and $\mathrm{H} 3$ and $\mathrm{H} 4$ acetylation are modulated [39].

\section{Other histone modifications}

So far, only one report exists investigating the functional interaction of sumoylation and epigenetic changes in RASF. RASF have intrinsically high levels of the small ubiquitin like modifier (SUMO)-1 paralleled by decreased levels of its specific protease SENP1. Transient 
overexpression of SENP1 in RASF reduced H4 acetylation in the MMP1 promoter and consequently MMP1 expression, leading to a decreased invasiveness. The authors further showed that the mechanism was dependent on the presence of HDAC4 [40].

With respect to the epigenetic modifications regulated by microRNAs we refer to our latest review on this subject [41].

\section{Conclusions}

In recent years, altered DNA methylation patterns and histone modifications including acetylation, methylation and sumoylation emerged as contributors in the pathogenesis of RA. The field of epigenetics has great potential of finding completely new targets for the treatment of RA. So far, most results are based on in vitro data and only little information exists about in vivo mechanisms. Available in vivo studies are based on the usage of HDAC inhibitors, which have, as recent in vitro studies showed, many non-epigenetic effects. For many histone modifications the data about their role in the pathogenesis of RA is insufficient and there is a complete lack of information about the interaction of different epigenetic mechanisms. Based on available evidence, targeting the aberrant methylation pattern found in RASF appears a promising treatment option to reverse the intrinsic activation, although in vivo work needs to be done to confirm this.

\section{Acknowledgements}

This work was supported by a grant of IAR, and by the IMI funded project BeTheCure $(115142-2)$.

\section{References and recommended reading}

Papers of particular interest, published within the period of review, have been highlighted as as:

$\left({ }^{*}\right)$ of special interest

$\left({ }^{* *}\right)$ of outstanding interest

[1] Neumann E, Lefevre S, Zimmermann B, Gay S, Muller-Ladner U: Rheumatoid arthritis progression mediated by activated synovial fibroblasts. Trends Mol Med 2010, 16:458468. $\left({ }^{*}\right)$ This review summerizes all aspects of the activated phenotype of rheumatoid arthritis synovial fibroblasts. 
[2] Lefevre S, Knedla A, Tennie C, Kampmann A, Wunrau C, Dinser R, Korb A, Schnaker EM, Tarner IH, Robbins PD, et al.: Synovial fibroblasts spread rheumatoid arthritis to unaffected joints. Nat Med 2009, 15:1414-1420

[3] Bird A: Perceptions of epigenetics. Nature 2007, 447:396-398

[4] Jakovcevski M, Akbarian S: Epigenetic mechanisms in neurological disease. Nat Med 2012, 18:1194-1204

[5] Bannister AJ, Kouzarides T: Regulation of chromatin by histone modifications. Cell Res 2011, 21:381-395

[6] Jones PA: Functions of DNA methylation: islands, start sites, gene bodies and beyond. Nat Rev Genet 2012, 13:484-492

[7] Margueron R, Reinberg D: The Polycomb complex PRC2 and its mark in life. Nature 2011, 469:343-349

[8] Kooistra SM, Helin K: Molecular mechanisms and potential functions of histone demethylases. Nat Rev Mol Cell Biol 2012, 13:297-311

[9] Karouzakis E, Gay RE, Michel BA, Gay S, Neidhart M: DNA hypomethylation in rheumatoid arthritis synovial fibroblasts. Arthritis Rheum 2009, 60:3613-3622

[10] Nakano K, Whitaker JW, Boyle DL, Wang W, Firestein GS: DNA methylome signature in rheumatoid arthritis. Ann Rheum Dis 2012.( $\left(^{*}\right)$ The authors provide a genome-wide evaluation of DNA methylation patterns in rheumatoid arthritis synovial fibroblasts that distinguish them from osteoarthritis and normal synovial fibroblasts.

[11] Liu CC, Fang TJ, Ou TT, Wu CC, Li RN, Lin YC, Lin CH, Tsai WC, Liu HW, Yen JH: Global DNA methylation, DNMT1, and MBD2 in patients with rheumatoid arthritis. Immunol Lett 2011, 135:96-99

[12] Karouzakis E, Gay RE, Gay S, Neidhart M: Increased recycling of polyamines is associated with global DNA hypomethylation in rheumatoid arthritis synovial fibroblasts. Arthritis Rheum 2012, 64:1809-1817.(**) The authors provide a concept how an increased polyamine metabolism in rheumatoid arthritis synovial fibroblasts causes global DNA hypomethylation and contributes to the intrinsic activation ot these cells.

[13] Takami N, Osawa K, Miura Y, Komai K, Taniguchi M, Shiraishi M, Sato K, Iguchi T, Shiozawa K, Hashiramoto A, et al.: Hypermethylated promoter region of DR3, the death receptor 3 gene, in rheumatoid arthritis synovial cells. Arthritis Rheum 2006, 54:779-787 [14] Nile CJ, Read RC, Akil M, Duff GW, Wilson AG: Methylation status of a single CpG site in the IL6 promoter is related to IL6 messenger RNA levels and rheumatoid arthritis. Arthritis Rheum 2008, 58:2686-2693

[15] Ishida K, Kobayashi T, Ito S, Komatsu Y, Yokoyama T, Okada M, Abe A, Murasawa A, Yoshie $\mathrm{H}$ : Interleukin-6 gene promoter methylation in rheumatoid arthritis and chronic periodontitis. J Periodontol 2012, 83:917-925 
[16] Fu LH, Ma CL, Cong B, Li SJ, Chen HY, Zhang JG: Hypomethylation of proximal CpG motif of interleukin-10 promoter regulates its expression in human rheumatoid arthritis. Acta Pharmacol Sin 2011, 32:1373-1380

[17] Lin SY, Hsieh SC, Lin YC, Lee CN, Tsai MH, Lai LC, Chuang EY, Chen PC, Hung CC, Chen LY, et al.: A whole genome methylation analysis of systemic lupus erythematosus: hypomethylation of the IL10 and IL1R2 promoters is associated with disease activity. Genes Immun 2012, 13:214-220

[18] Karouzakis E, Rengel Y, Jungel A, Kolling C, Gay RE, Michel BA, Tak PP, Gay S, Neidhart M, Ospelt C: DNA methylation regulates the expression of CXCL12 in rheumatoid arthritis synovial fibroblasts. Genes Immun 2011, 12:643-652

[19] Chabchoub G, Uz E, Maalej A, Mustafa CA, Rebai A, Mnif M, Bahloul Z, Farid NR, Ozcelik T, Ayadi H: Analysis of skewed X-chromosome inactivation in females with rheumatoid arthritis and autoimmune thyroid diseases. Arthritis Res Ther 2009, 11:R106 [20] Liao J, Liang G, Xie S, Zhao H, Zuo X, Li F, Chen J, Zhao M, Chan TM, Lu Q: CD40L demethylation in CD4(+) T cells from women with rheumatoid arthritis. Clin Immunol 2012, 145:13-18

[21] Trenkmann M, Brock M, Gay RE, Kolling C, Speich R, Michel BA, Gay S, Huber LC:

Expression and function of EZH2 in synovial fibroblasts: epigenetic repression of the Wnt inhibitor SFRP1 in rheumatoid arthritis. Ann Rheum Dis 2011, 70:1482-1488.(*) This is the first study describing a functional role of histone methylation in rheumatoid arthritis synovial fibroblasts.

[22] Dai Y, Zhang L, Hu C, Zhang Y: Genome-wide analysis of histone H3 lysine 4 trimethylation by ChIP-chip in peripheral blood mononuclear cells of systemic lupus erythematosus patients. Clin Exp Rheumatol 2010, 28:158-168

[23] Kramer M, Dees C, Huang J, Schlottmann I, Palumbo-Zerr K, Zerr P, Gelse K, Beyer C, Distler A, Marquez VE, et al.: Inhibition of H3K27 histone trimethylation activates fibroblasts and induces fibrosis. Ann Rheum Dis 2012,

[24] Joosten LA, Leoni F, Meghji S, Mascagni P: Inhibition of HDAC activity by ITF2357 ameliorates joint inflammation and prevents cartilage and bone destruction in experimental arthritis. Mol Med 2011, 17:391-396

[25] Lin HS, Hu CY, Chan HY, Liew YY, Huang HP, Lepescheux L, Bastianelli E, Baron R, Rawadi G, Clement-Lacroix P: Anti-rheumatic activities of histone deacetylase (HDAC) inhibitors in vivo in collagen-induced arthritis in rodents. Br J Pharmacol 2007, 150:862872

[26] Nasu Y, Nishida K, Miyazawa S, Komiyama T, Kadota Y, Abe N, Yoshida A, Hirohata S, Ohtsuka A, Ozaki T: Trichostatin A, a histone deacetylase inhibitor, suppresses 
synovial inflammation and subsequent cartilage destruction in a collagen antibodyinduced arthritis mouse model. Osteoarthritis Cartilage 2008, 16:723-732

[27] Nishida K, Komiyama T, Miyazawa S, Shen ZN, Furumatsu T, Doi H, Yoshida A, Yamana J, Yamamura M, Ninomiya Y, et al.: Histone deacetylase inhibitor suppression of autoantibody-mediated arthritis in mice via regulation of p16INK4a and p21(WAF1/Cip1) expression. Arthritis Rheum 2004, 50:3365-3376

[28] Saouaf SJ, Li B, Zhang G, Shen Y, Furuuchi N, Hancock WW, Greene MI: Deacetylase inhibition increases regulatory $\mathrm{T}$ cell function and decreases incidence and severity of collagen-induced arthritis. Exp Mol Pathol 2009, 87:99-104

[29] Huber LC, Brock M, Hemmatazad H, Giger OT, Moritz F, Trenkmann M, Distler JH, Gay $\mathrm{RE}$, Kolling $\mathrm{C}$, Moch $\mathrm{H}$, et al.: Histone deacetylase/acetylase activity in total synovial tissue derived from rheumatoid arthritis and osteoarthritis patients. Arthritis Rheum 2007, 56:1087-1093

[30] Kawabata T, Nishida K, Takasugi K, Ogawa H, Sada K, Kadota Y, Inagaki J, Hirohata S, Ninomiya $Y$, Makino $\mathrm{H}$ : Increased activity and expression of histone deacetylase 1 in relation to tumor necrosis factor-alpha in synovial tissue of rheumatoid arthritis.

Arthritis Res Ther 2010, 12:R133

[31] Horiuchi M, Morinobu A, Chin T, Sakai Y, Kurosaka M, Kumagai S: Expression and function of histone deacetylases in rheumatoid arthritis synovial fibroblasts. $J$ Rheumatol 2009, 36:1580-1589

[32] Grabiec AM, Reedquist KA: Histone deacetylases in RA: epigenetics and epiphenomena. Arthritis Res Ther 2010, 12:142

[33] Niederer F, Ospelt C, Brentano F, Hottiger MO, Gay RE, Gay S, Detmar M, Kyburz D: SIRT1 overexpression in the rheumatoid arthritis synovium contributes to proinflammatory cytokine production and apoptosis resistance. Ann Rheum Dis 2011, 70:1866-1873.(*) The authors demonstrate a specific function of SIRT1 in rheumatoid arthritis synovial fibroblasts and monocytes in inflammation and apoptosis by overexpression and knock down experiments.

[34] Gillespie J, Savic S, Wong C, Hempshall A, Inman M, Emery P, Grigg R, McDermott MF: Histone deacetylases are dysregulated in rheumatoid arthritis and a novel histone deacetylase 3-selective inhibitor reduces interleukin-6 production by peripheral blood mononuclear cells from rheumatoid arthritis patients. Arthritis Rheum 2012, 64:418-422 [35] Grabiec AM, Krausz S, de Jager W, Burakowski T, Groot D, Sanders ME, Prakken BJ, Maslinski W, Eldering E, Tak PP, et al.: Histone deacetylase inhibitors suppress inflammatory activation of rheumatoid arthritis patient synovial macrophages and tissue. J Immunol 2010, 184:2718-2728 
[36] Singh BN, Zhang G, Hwa YL, Li J, Dowdy SC, Jiang SW: Nonhistone protein acetylation as cancer therapy targets. Expert Rev Anticancer Ther 2010, 10:935-954 [37] Grabiec AM, Korchynskyi O, Tak PP, Reedquist KA: Histone deacetylase inhibitors suppress rheumatoid arthritis fibroblast-like synoviocyte and macrophage IL-6 production by accelerating mRNA decay. Ann Rheum Dis 2012, 71:424-431.(**) This paper shows an epigenetic-independent mechanism of HDAC inhibitor function in rheumatoid arthritis synovial fibroblasts and macrophages.

[38] Choo QY, Ho PC, Tanaka Y, Lin HS: Histone deacetylase inhibitors MS-275 and SAHA induced growth arrest and suppressed lipopolysaccharide-stimulated NFkappaB p65 nuclear accumulation in human rheumatoid arthritis synovial fibroblastic E11 cells. Rheumatology (Oxford) 2010, 49:1447-1460

[39] Dashwood RH, Ho E: Dietary histone deacetylase inhibitors: from cells to mice to man. Semin Cancer Biol 2007, 17:363-369

[40] Maciejewska-Rodrigues H, Karouzakis E, Strietholt S, Hemmatazad H, Neidhart M, Ospelt C, Gay RE, Michel BA, Pap T, Gay S, et al.: Epigenetics and rheumatoid arthritis: the role of SENP1 in the regulation of MMP-1 expression. J Autoimmun 2010, 35:15-22 [41] Filkova M, Jungel A, Gay RE, Gay S: MicroRNAs in rheumatoid arthritis: potential role in diagnosis and therapy. BioDrugs 2012, 26:131-141 


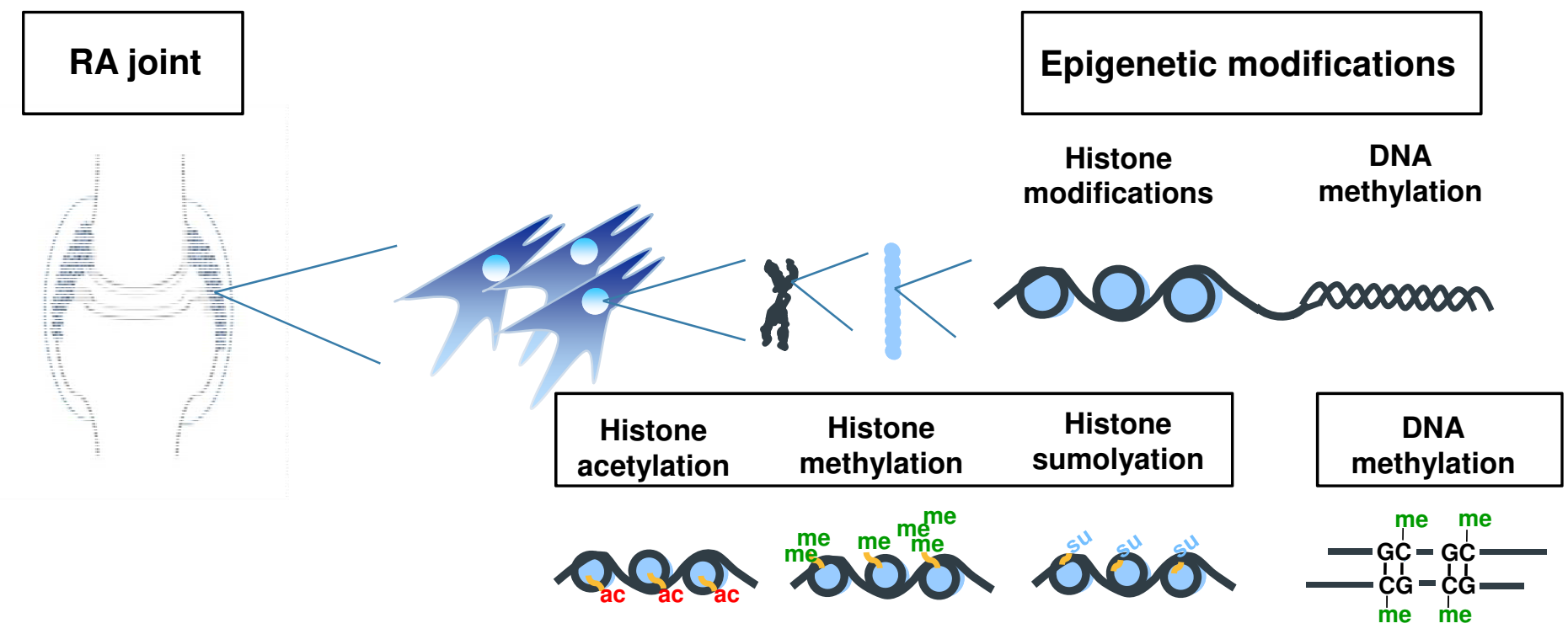




\begin{tabular}{|c|c|c|c|c|c|}
\hline & & $\begin{array}{l}\text { Histone } \\
\text { acetylation }\end{array}$ & $\begin{array}{c}\text { Histone } \\
\text { methylation }\end{array}$ & $\begin{array}{c}\text { Histone } \\
\text { sumolyation }\end{array}$ & $\begin{array}{c}\text { DNA } \\
\text { methylation }\end{array}$ \\
\hline & Synovial fibroblasts & $\begin{aligned} & \text { HDACs } \downarrow \uparrow \\
&- \text { SIRT1 } \uparrow \\
& \stackrel{\text { LPS }}{\longrightarrow} \text { IL6 } \\
&\end{aligned}$ & $\complement_{\text {SFRP1 }}^{\text {EZH2 } \downarrow}$ & $\oint_{\text {MMP1 }}^{\text {SENP1 }}$ & 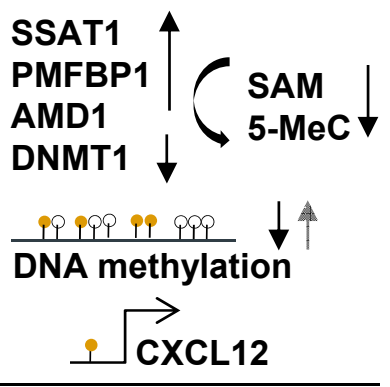 \\
\hline & Macrophages & $\begin{array}{l}\stackrel{\mathrm{LPS}}{\longrightarrow} \text { IL6 } \\
\mathrm{TNF}-\mathrm{a} \\
\stackrel{\mathrm{TNF}-\mathrm{a}}{\longrightarrow} \text { IL6 }\end{array}$ & & & $\stackrel{\overrightarrow{I L 6}}{ }$ \\
\hline $\begin{array}{l}\because \text { cytokines } \\
\ulcorner\text { MMPs } \\
\longrightarrow \text { promoter } \\
\rightarrow \text { treatment }\end{array}$ & 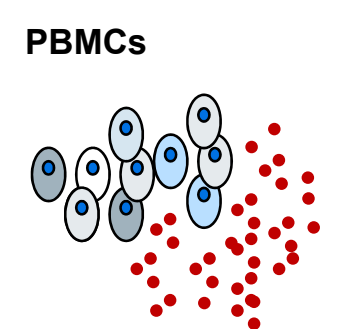 & $\stackrel{\mathrm{LPS}}{\longrightarrow}{ }_{\mathrm{IL} 1 \beta}^{\mathrm{TNF}-\mathrm{o}}$ & & & 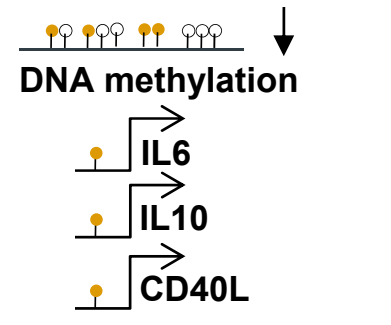 \\
\hline
\end{tabular}




\section{Figure legends}

Figure 1: Epigenetic modifications such as DNA methylation and histone modifications of rheumatoid arthritis synovial fibroblasts (RASF) contribute to their intrinsic activation and aggressive phenotype. ac, acetylation; me; methylation; su, sumoylation;

Figure 2: Epigenetic mechanisms and downstream targets identified in rheumatoid synovial fibroblasts, macrophages and peripheral blood mononuclear cells (PBMCs). HDACs, histone deacetylases; SIRT1, Sirtuin1; LPS, lipopolysaccharide; IL, interleukin; TNF- $\alpha$, tumor necrosis factor- $\alpha$; EZH2, histone methyltransferase enhancer of zeste homologue 2; SFRP1, secreted frizzled-related protein 1; SENP1, SUMO specific protease 1; MMP1, metalloproteinase 1; SSAT, spermidine/ spermine N1-acetyltransferase; PMFBP1, polyamine-modulated factor 1-binding protein 1; AMD1, S-adenosyl methionine decarboxylase; DNMT1, DNA methyltransferase 1; SAM, S-adenosyl methionine; 5-MeC, 5methylcytosine; CXCL12, chemokine (C-X-C motif) ligand 12; CD40 L, CD40 ligand; 


\begin{tabular}{|c|c|c|c|c|}
\hline Epigenetic modification & Target(s) & Drug & Findings & References \\
\hline DNA methylation & DNMT1 & 5-azacytidine (5-azaC) & $\begin{array}{l}\text { Treatment of normal SF } \\
\text { reproduced the RASF phenotype }\end{array}$ & [8] \\
\hline $\begin{array}{l}\text { Histone methylation } \\
\text { H3K27me3 }\end{array}$ & Polycomb repressor complex & $\begin{array}{l}\text { 3-deazaneplanocin } \\
\text { (DZNep) }\end{array}$ & not tested in RA & \\
\hline \multirow[t]{4}{*}{ Histone acetylation } & $\begin{array}{l}\text { Class I (HDAC 1,2,3,8) and Class II } \\
\text { (HDAC 4,5,6,7,9,10) HDACs } \\
\text { Class III (Sirtuins; SIRT1-7) }\end{array}$ & $\begin{array}{l}\text { Trichostatin A (TSA) } \\
\text { Nicotinamide }\end{array}$ & $\begin{array}{l}\text { Reduced TNF- } \alpha \text { induced IL-6 } \\
\text { expression and reduced LPS } \\
\text { induced IL- } 6 \text { and TNF- } \alpha \\
\text { expression in macrophages; } \\
\text { Induction of apoptosis in } \\
\text { macrophages }\end{array}$ & [34] \\
\hline & HDAC3 & MI192 & $\begin{array}{l}\text { Reduced LPS-induced IL-6 } \\
\text { production in PBMCs from RA } \\
\text { patients }\end{array}$ & [33] \\
\hline & Class I and Class II HDACs & $\begin{array}{l}\text { TSA } \\
\text { ITF2357 (Givinostat) }\end{array}$ & $\begin{array}{l}\text { Reduced IL- } 6 \text { mRNA stability in } \\
\text { macrophages and RASF }\end{array}$ & [36] \\
\hline & $\begin{array}{l}\text { HDAC1, HDAC3 } \\
\text { Class I and Class II HDACs }\end{array}$ & $\begin{array}{l}\text { MS-275 (Entinostat) } \\
\text { Suberoylanilide } \\
\text { hydroxamic acid } \\
\text { (SAHA, Vorinostat) }\end{array}$ & $\begin{array}{l}\text { Suppressed LPS-induced nuclear } \\
\text { accumulation of NF-KB p } 65 \text { in } \\
\text { synovial fibroblastic E11 cells } \\
\text { and THP-1 monocytes }\end{array}$ & [37] \\
\hline
\end{tabular}

Table 1: Experimentally used drugs targeting epigenetic modifications in rheumatoid arthritis. 


\section{Highlights}

- RA synovial fibroblasts display an aberrant DNA methylome signature

- Histone deacetylase inhibitors have beneficial effects in RA

- Histone deacetylase inhibitors have epigenetic and non-epigenetic effects 